Saudi Journal of Oral and Dental Research

Abbreviated Key Title: Saudi J Oral Dent Res

ISSN 2518-1300 (Print) |ISSN 2518-1297 (Online)

Scholars Middle East Publishers, Dubai, United Arab Emirates

Journal homepage: https://saudijournals.com/sjodr

\title{
Attitude and Perception of Undergraduate Dental Students towards Endodontics as a Speciality
}

Dr. Albi Ngjelo, BDS ${ }^{1 *}$, Dr. Keertana Rao, BDS ${ }^{2}$, Dr. Swathi Mannepula, BDS ${ }^{3}$, Dr. Charmiben Patel, BDS ${ }^{4}$, Dr. Aditi Gadhvi, BDS ${ }^{4}$, Dr. Divija Takkalapelly, BDS ${ }^{5}$

${ }^{1}$ New York, US

${ }^{2}$ A. B. Shetty Memorial Institute of Dental Sciences, Mangalore, India

${ }^{3}$ Texas, US

${ }^{4}$ K. M. Shah Dental College and Hospital, Gujarat, India

${ }^{5}$ Government Dental College and Hospital, Telangana, India

DOI: $10.36348 /$ sjodr.2020.v05i03.006

| Received: 03.02.2020 | Accepted: 07.03.2020 | Published: 18.03.2020

*Corresponding author: Dr. Albi Ngjelo

\section{Abstract}

Background: For choosing a specialty subject for post graduate studies, students' attitude is of great importance for the education system. Aim \& Objectives: In order to evaluate the perception and attitude of dental students toward learning, contributing in the treatment, choosing endodontics as a specialty for post-graduate studies. Materials and Methods: The present article is about a semi structured questionnaire study survey in which 10 multiple-choice questions was compiled and distributed among 403 undergraduate dental clinical students. The main domains appraised in the questionnaire were preclinical as well as clinical training in the endodontics, their interest and opinion in endodontics as a post-graduate specialty. The statistical analysis was done by one sample chi-square test in order to see the association of subject response toward the endodontics as a specialty response to each question. Results: Response rate was $74.5 \%$ and the results showed that $72 \%$ of students preferred the preclinical training on extracted human teeth while $71 \%$ of the students believed that the intense preclinical training will help them to manage the patients confidently. Conclusion: The prime conclusion of the present study revealed that the majority of students find endodontics as an interesting subject to study and also they would opt for endodontics for post graduation.

Keywords: Dental students, endodontics, perception, preclinical, specialty.

Copyright @ 2020: This is an open-access article distributed under the terms of the Creative Commons Attribution license which permits unrestricted use, distribution, and reproduction in any medium for non-commercial use (NonCommercial, or CC-BY-NC) provided the original author and source are credited.

\section{INTRODUCTION}

Currently, the scope of endodontics has vastly broadened. The vital pulp therapy including regeneration of pulpal and periradicular tissues as well as stem cell treatment, moreover, MRI, CBCT, PCR, Doppler's have changed the scope of diagnosis as well as the treatment planning for the oral lesions of pulp and periapical origin. The nonsurgical approach of root canal therapy and microsurgical procedures remove the pathological tissues optimally with the minimal intervention. This specialty also encompasses the bleaching of discolored teeth, endodontic implants, management of traumatically injured teeth, re-treatment of previously endodontically treated teeth with special instruments and post-endodontic rehabilitation of teeth with more preservation of tissues [1]. Unfortunately, the endodontics is synonymous with root canal treatment among the undergraduate students. Endodontics as a specialty is at a crucial phase with rapid changes seen in biomaterials, biosciences and instrumentation. One of the basic concerns as dental educators is to train students who are not only uncomfortable with techniques of clinical dentistry, but are also not very competent in diagnosis to improve the quality of life for their patients [2]. Endodontics is considered as a stressful and difficult discipline by the students. The inability to visualize the root canal, complex anatomical diversity and dependence on the tactile feel as well as the array of materials and instruments tends to make several students feel inadequately prepared to deal with the endodontic treatment procedures. Thereby, this insecurity may also reflect insufficient clinical and informative teaching in the dental curriculum [3]. Hence, in order to prepare the students, it is the responsibility of dental schools to prepare their students to undertake at least simple root canal treatments of predictable quality on graduation [4]. Although in many countries, in endodontics, the undergraduate (UG) training is limited to the diagnosis of endodontic lesions, root canal and simple vital pulp therapy for the 
anterior teeth. The undergraduate students and interns are considered apprentice, thereby, it is essential that educators understand what should be the extent of the endodontic training that has to be imparted to students before they graduate, thereby they will be able to render the basic endodontic treatment. The present study is to evaluate the fourth year students as well as interns' perception and attitude toward learning, in rendering the endodontic treatment and choosing endodontics as a specialty for post-graduation as well as the general opinion of this specialty.

\section{MATERIALS AND METHODS}

The present survey used semi structured, pretested, self administered questionnaire composed with 10 multiple choice questions was distributed among many undergraduate dental students and interns of various dental college. A pilot study was conducted in order to check the reliability and feasibility of questionnaire. A total of 400 dental clinical students were included in the study which comprised of fourth year undergraduate students and interns. The students filled out the questions. All the answers were kept confidential and no individual students were identified. Once completed, there was no re-participation of the students in the survey. The questionnaire elicited the information regarding the demography and the 10 items assessing the perception as well as the attitude of the undergraduate dental students towards the endodontics as a specialty. Prior to the questionnaire administration, informed consent was obtained. The sample size was calculated by using the formula. $n=4 \mathrm{pq} l 2$ Where, $P=$ Perception of students to opt for endodontics is assumed to be $50 \% q=(1-p) l=$ Allowable error at $5 \% n=$ 400.The final data of the survey results were compiled and submitted for statistical analysis. Data obtained from the study were statistically analyzed by using the Statistical Package for the Social Sciences (SPSS) version 16.0 in order to calculate the descriptive statistics. A sample chi-square test was also done in order to see the association of subject response towards the endodontic as a specialty response to each question.

\section{RESULTS \& DISCUSSION}

A total of 403 students were invited for the participation in the survey. Out of that, 300 of the students returned the completed questionnaire. The overall response rate was $75 \%$. The participant population sample consisted of $40 \%$ males and $60 \%$ percent females. $58 \%$ of the participants were of final year students and $42 \%$ were interns. All the questions have shown statistically significant result with $P$-value less than 0.01 . The analysis for question related to the perception of preclinical endodontic training showed that $53 \%$ of the students perceived it is necessary to be trained in preclinical endodontics. Approximately 92\% of the students found endodontics as an interesting subject to study. About $73 \%$ of the students favored the preclinical training on extracted teeth and approximately $71 \%$ of the students suggested that after preclinical endodontic training, they can confidently do the endodontic procedures. About $87 \%$ of the students found that the root canal treatment is the most common endodontic procedure and $45 \%$ of the students agreed that the third year of the academic course is the best time in order to start the clinical endodontic training. The analysis of the questions regarding the diagnosis of pulpal and periapical lesions revealed that approximately $24 \%$ of the students were not sure although $52 \%$ responded in favor of confidence to diagnose the lesion correctly after the preclinical training. $92 \%$ of the students suggested that the endodontic educational aids such as 3-D interactive tooth, atlas models should be used as educational adjuvants. $67 \%$ of the students viewed the specialty of endodontics highly and about $84 \%$ of the participants suggested that they would like to persuade it as post graduate specialty. With the advent of rapid changes taking place in the treatment techniques as well as the materials in the field of endodontics, it is of great importance that UG students are equipped with the understanding as well as the preclinical experience while using these materials and instruments before treating the patients. There is a wide range of variation in the way the endodontics has been taught and also the level of competencies developed in the undergraduates in various institutions across the world. ${ }^{5}$ According to Chambers, an improvement in the performance occurs as a student progresses through a series of learning processes [6]. Thereby, the educators need to recognize the problems and modify the curriculum during the designing and evaluation of the curriculum. While learning the new techniques, undergraduate dental students require to explicit directions as well as the instructions in small steps, as they work toward achieving the competence in performing more complex tasks in the clinical settings [7]. The present survey also revealed that the majority of the students i.e., approximately $90 \%$ find the branch of endodontics as an interesting dental subject. The cross infection controls as well as the ethical issues are the reasons for replacing the extracted human natural teeth with artificial teeth for preclinical endodontic training in some of the teaching institutions. Reader et al., demonstrated that difficulty of the standardization of natural teeth could also be another drawback [8]. Although this survey revealed that $73 \%$ of the students preferred extracted human natural teeth for the preclinical training as it helps them to better understand the complexities of root canal anatomy. A study by Nassri et al., evaluated that five cloudy resin artificial teeth for their external and internal anatomy, coronal chambers for their shape, size and canal path, root canals for their shape, size and position; the pulp chamber and root canals by considering their quality, color, texture and ease of handling; the resin hardness as well as the visualization of radiographic image and concluded that the artificial teeth have potential to replace the natural teeth in endodontic teaching; 
although, the improvements are still necessary in order to reach a better quality model [9]. About $88 \%$ of the students associated endodontics with the root canal treatment. However, there is a paradigm shift in the management of pulpal as well as periapical diseases with the emphasis on regenerative endodontics, vital pulp therapy, microsurgical procedures, non-vital bleaching for esthetics, post-endodontic restorations, endodontics as a part of the interdisciplinary treatment modalities thereby suggesting need to emphasis on these treatment modalities as well during the teaching of this specialty. Approximately 94\% students suggested that there should be a change in the teaching modality and methodology. The respondents also recommended that the endodontic educational aids such as models, 3-D interactive tooth atlas which combines the text, sound, video and stills with the interactive learning should be used as the educational adjuvant. Manny studies have suggested that the endodontic computer simulation programs results in the significant gain in the knowledge as well as can successfully replace the traditional learning strategies [10, 11]. According to Urbankova, computerized dental simulator training of eight hours conducted early in preclinical operative dentistry improved student performance and could also be true for the endodontic preclinical training [12]. Al-Jewai et al., in a systemic review concluded that the computer assisted learning is intended in order to support the traditional learning methods, however not to replace them [13]. About only $53 \%$ of the respondents believe that they have been trained in the preclinical endodontics using extracted teeth models. Around $70 \%$ students believed that the intense preclinical training will help them in order to manage the patients confidently. A study by Dhima et al., evaluated that the dental students perception on dental specialties and the factors that can play an important role in the students decision in order to pursue the career choices or the specialty training and concluded that enjoyment of providing care in a field or specialty was identified as the single most important factor in order to choose a specialty career [14]. 84\% participants in the present survey suggested that they would specialize in the field of endodontics if given an opportunity, which is a positive sign for the specialty.

\section{CONCLUSION}

The present study concluded that mostly the undergraduate students are interested in persuading endodontics as a postgraduate specialty. Thereby, the need of hour is to emphasize on the preclinical endodontic training as well as the clinical training for the management of all the pulpal as well as the periapical lesions with various and different modalities at the level of undergraduate curriculum. The endodontics is a vibrant, interesting as well as evolving clinical specialty. Thereby, an intense endodontic training at undergraduate level prepares the graduates to provide a good basic patient care in clinical practice.

\section{REFERENCES}

1. Ingle, J. I., Bakland, L. K., \& Baumgartner, J. C. (2008). Ingle's Endodontics 6. 6th ed. Hamilton, Ontario: BC Decker.

2. Pileggi, R., \& O'Neill, P. N. (2008). Team-based learning using an audience response system: an innovative method of teaching diagnosis to undergraduate dental students. Journal of dental education, 72(10), 1182-1188.

3. Rolland, S., Hobson, R., \& Hanwell, S. (2007). Clinical competency exercises: some student perceptions. European Journal of Dental Education, 11(3), 184-191.

4. Qualtrough, A. J. E., Whitworth, J. M., \& Dummer, P. M. H. (1999). Preclinical endodontology: an international comparison. International endodontic journal, 32(5), 406-414.

5. Friedlander, L., \& Anderson, V. (2011). A new predoctoral endodontic module: evaluating learning and effectiveness. Journal of dental education, 75(3), 351-359.

6. Chambers, D. W. (1993). Toward a competencybased curriculum. Journal of dental education, 57, 790-793.

7. Guenzel, P. J. (1995). Designing preclinical instruction for psychomotor skills (III)--Instructional engineering: design phase. Journal of dental education, 59(3), 412-418.

8. Reader, C. M., Kleier, D. J., \& Bujanda-Wagner, S. (1994). Anatomical artificial teeth for teaching preclinical endodontics. Journal of dental education, 58(3), 229-232.

9. Nassri, M. R. G., Carlik, J., Silva, C. R. N. D., Okagawa, R. E., \& Lin, S. (2008). Critical analysis of artificial teeth for endodontic teaching. Journal of Applied Oral Science, 16(1), 43-49.

10. Fouad, A. F., \& Burleson, J. A. (1997). Effectiveness of an endodontic diagnosis computer simulation program. Journal of dental education, 61(3), 289295.

11. Plasschaert, A. J., Cailleteau, J. G., \& Verdonschot, E. H. (1997). The effect of a multimedia interactive tutorial on learning endodontic problemsolving. European Journal of Dental Education, 1(2), 66-69.

12. Urbankova, A. (2010). Impact of computerized dental simulation training on preclinical operative dentistry examination scores. Journal of Dental Education, 74(4), 402-409.

13. Al-Jewair, T. S., Qutub, A. F., Malkhassian, G., \& Dempster, L. J. (2010). A systematic review of computer-assisted learning in endodontics education. Journal of Dental Education, 74(6), 601611.

14. Dhima, M., Petropoulos, V. C., Han, R. K., Kinnunen, T., \& Wright, R. F. (2012). Dental students' perceptions of dental specialties and factors influencing specialty and career choices. Journal of dental education, 76(5),

$562-573$. 